\title{
Caracterização morfotintorial de Colletotrichum spp. causador de antracnose em frutos de figo cultivados experimentalmente no perímetro irrigado de São Gonçalo, Sousa-PB
}

\section{Morphologic and dyeing of Colletotrichum spp. causing anthracnose fruit of fig grown experimentally in the irrigation of São Gonçalo, Sousa-PB}

\author{
Damião Junior Gomes ${ }^{1}$, Oscar Mariano Hafle ${ }^{2}$, Nelieide Medeiros Gomes ${ }^{3}$, Antonia Mendes Meira Fernandes ${ }^{4}$ Patrício \\ Borges Maracajá ${ }^{5}$
}

\begin{abstract}
RESUMO: Como alternativa da inserção de novas culturas na região do Semiárido brasileiro temos o figo 'Roxo de Valinhos' (Ficus carica L.) uma planta família Moraceae que pode muito bem ser inserida no contexto da agricultura familiar, mas que vem sofrendo infecção por um fungo do gênero Colletotrichum provocando importantes percas econômicas no agronegócio e também no campo da pesquisa e extensão. Este trabalho teve como objetivo caracterizar a morfologia de isolados de Colletotrichum spp. causador de antracnose pós-colheita em frutos de Ficus carica L. cultivado experimentalmente no perímetro irrigado da São Gonçalo no município de Sousa-PB. Primeiramente identificou os frutos com sintomas de antracnose seguido de sua desinfecção com álcool a 70\%. Logo fez-se montagem em lâmina de microscopia para um prévia avaliação do patógeno. $\mathrm{O}$ fungo foi isolado em Batata-Dextrose-Ágar a $25^{\circ} \mathrm{C}$ durante 10 dias. Seguidamente foi feito o microcultivo no mesmo meio de cultura para a análise morfo-tintorial do micélio usando como corante azul de algodão e lactofenol de amann.
\end{abstract}

Palavras-chave: Ficus carica, podridão, Colletotrichum, microcultivo.

\begin{abstract}
Como alternativa da inserção de novas culturas na região do Semiárido brasileiro temos o figo Alternatively the introduction of new crops in the semiarid region of Brazil have the fig 'Roxo de Valinhos' ( Ficus carica L.), a plant family Moraceae that may well be placed in the context of family farming, but has suffered a fungal infection the genus Colletotrichum causing important economic losses in agribusiness and also in research and extension. This study aimed to characterize the morphology of Colletotrichum spp . causing anthracnose postharvest fruits of Ficus carica L. experimentally grown in the irrigated area in the municipality of São Gonçalo de Sousa -PB . First identified fruit with anthracnose symptoms followed by disinfection with a $70 \%$ alcohol. Soon made up mount microscope slide for prior assessment of the pathogen . The fungus was isolated on Potato Dextrose Agar at $25^{\circ} \mathrm{C}$ for 10 days. Then microculture was made in the same medium for analysis Morphological and dyeing the mycelium using as blue dye lactophenol cotton and amann .
\end{abstract}

Key words: Ficus carica, rot, Colletotrichum, microcultive.

\footnotetext{
*Autor para correspondência

Recebido para publicação em 15/01/2015; aprovado em 25/02/2015

${ }^{1}$ Farmacêutico, Mestre em Sistemas Agroindustriais UFCG CCTA Campus Pombal, Servidor Técnico -Administrativo Laboratório de Análises

Microbiológicas de Alimentos Instituto Federal da Paraíba - IFPB Campus Sousa . E-mail: damiaojuniorgomes@yahoo.com.br

${ }^{2}$ Licenciado em Ciências Agrícolas D. Sc., Professor do Ensino Técnico e Tecnológico Instituto Federal da Paraíba Campus Sousa

${ }^{3}$ Estudante de Farmácia, Faculdade São Francisco da Paraíba Cajazeiras -PB

${ }^{4}$ Estudante de Farmácia, Faculdade São Francisco da Paraíba Cajazeiras -PB

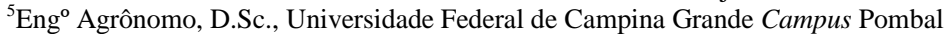




\section{INTRODUÇÃO}

A figueira é uma frutífera de expressão econômica para o Brasil. É uma árvore da família Moraceae, originária da região do Mediterrâneo e trata-se de umas das primeiras plantas cultivadas pelo homem. É uma planta perene com porte arbustivo, que inicia a produção após um ano de plantio no campo (MAIORANO, 2010).

Segundo Leonel \& Tecchio (2010) o Brasil é atualmente, o segundo maior exportador de frutos in natura do mundo, e, no Estado de São Paulo a cultura está concentrada na região de Valinhos-Campinas e seu cultivo é realizado principalmente por agricultores familiares.

Ainda conforme Leonel \& Tecchio (2010), a figueira por ser originária da região mediterrânica, onde predomina clima subtropical temperado, é uma planta que se adapta aos diferentes climas, sendo cultivada em regiões subtropicais, temperadas e inclusive, pela sua baixa exigência pelo frio pode levar a valorização das terras e da grande urbanização da região produtora original.

Kotz e colaboradores (2011) relatam que a preferência por comercializar apenas o figo 'Roxo de Valinhos' (Ficus carica L.), tem trazido sérios problemas aos ficicultores de do interior de São Paulo, devido à ocorrência de sérios problemas fitossanitários incluindo entre os principais alguns nematoides como Meloidogyne incógnita e Heterodera fici, a ferrugem da figueira causada por Cerotelium fici e a seca devida a presença de Ceratocystis fimbriata.

A antracnose é uma doença causada pelo fungo Colletotrichum spp. que infecta grande variedade de plantas. Razão pela qual o estudo deste patógeno possui elevado interesse econômico em plantas de diversas famílias botânicas. $\mathrm{O}$ fungo ataca principalmente frutos e os sintomas da doença são caracterizados pela presença de lesões circulares e deprimidas, de tamanho variável, as vezes com a presença de uma massa de conídios, normalmente alaranjada. A doença se desenvolve principalmente em clima quente e úmidos. Estes sintomas podem aumentar na fase de póscolheita, o que elevam ainda mais os prejuízos, devido ao fato de os frutos já estarem preparados para a comercialização (SOUSA, SERRA \& MELO, 2012).

O sintoma típico de da doença antracnose é caracterizado por lesões grandes e arredondado, necrótico e bordos elevados com o centro dos tecidos deprimidos. O fungo do gênero Colletotrichum penetra frutos ainda verde, este por sua vez permanece inativo até amadurecer (BONETT et al, 2010).

Não é tão fácil identificar espécie do gênero Colletotrichum, pois, esta apresenta poucas características morfológicas distinguíveis e as fases taleomórfas quase não são formadas (LÓPEZ, 2001).
O objetivo deste trabalho foi caracterizar a morfologia de isolados de Colletotrichum spp. causador de antracnose pós-colheita em frutos de Ficus carica $L$. cultivado experimentalmente no perímetro irrigado da São Gonçalo no município de Sousa-PB.

\section{MATERIAIS E MÉTODOS}

Os isolados de Colletotrichum spp. foram obtidos de furtos maduros de Ficus carica $L$. cultivados na escolafazenda o Instituto Federal da Paraíba, Campus Sousa (IFPBSousa), localizado no Perímetro Irrigado de São Gonçalo $\left(6^{\circ}\right.$ $45^{\prime} \mathrm{S}$ de latitude, $38^{\circ} 13^{\prime} \mathrm{W}$ de longitude e altitude $223 \mathrm{~m}$ ), no período de dezembro de 2011 a abril de 2012. Os frutos identificados com sintomas típicos da doença foram desinfestados com álcool a $70 \%$ por dois minutos, retirandose o excesso com papel toalha. A etapa seguinte foi à montagem de lâmina e observação em microscopia óptica para uma prévia avaliação morfológica do patógeno (BONNET et al, 2010).

Em seguida, através do método direto obteve o isolado do fungo utilizando Batata-Dextrose-Ágar (BDA), cujos esporos foram inoculados no meio de cultura citado acondicionado em uma Placa de Petri e cultivados sobre uma temperatura de $25^{\circ} \mathrm{C}$ com variação de $2^{\circ} \mathrm{C}$ em uma incubadora BOD durante dez dias (BONNET et al, 2010).

Do crescimento obtido, foram feitas repicagens em meio BDA, submerso com óleo mineral. Este procedimento foi necessário para a conservação das amostras (BONNET et $a l, 2010)$.

Para a análise micelial, procedeu-se o microcultivo em meio BDA. Neste caso a avaliação foi feita após as 24 horas (BONNET et al, 2010).

As análises morfo-tintoriais dos micelos foram realizadas pela coloração com azul de algodão e lactofenol de amann (PERES et al, 2003).

\section{RESULTADOS E DISCUSSÃO}

A tabela 1 expressa a média do tamanho das lesões medido em 12 frutos maduros nos seis meses de pesquisa. A maior lesão foi obervada no último mês. As cores das colônias dos fungos variaram entre branco e salmão e ainda apresentaram tons de cinza. O pigmento branco predominou nos primeiros dias seguindo variações posteriores. Foram observados conídios agrupados formando uma massa de coloração de cor salmão e empalidecido semelhante a descrição feita Brand et al (2010) em seu trabalho sobre o uso de extratos de alho e alecrim na indução de faseolina em feijoeiro e fungitoxicidade sobre Colletotrichum lindemuthianum.

Tabela 1: Média em centímetro do tamanho das lesões em frutos maduros de Ficus carica L. cultivados entre novembro de 2011 e abril de 2012.

\begin{tabular}{cccccc}
\hline Novembro & Dezembro & Janeiro & Fevereiro & Março & Abril \\
\hline 3,04 & 2,85 & 2,94 & 3,45 & 3,60 & 3,65 \\
\hline
\end{tabular}

Tabela 2: Coloração das bordas do micélio do isolados Colletotrichum spp em frutos maduros Ficus carica L. cultivados entre novembro de 2011 e abril de 2012.

\begin{tabular}{cccccc}
\hline Novembro & Dezembro & Janeiro & Fevereiro & Março & Abril \\
\hline Branca & Banca & Branca/cinza & Branca/cinca & Cinza & Cinza \\
\hline
\end{tabular}


Caracterização morfotintorial de Colletotrichum spp. causador de antracnose em frutos de figo cultivados experimentalmente no perímetro irrigado de São Gonçalo, Sousa-PB

Tabela 3: Coloração da massa conidial do isolados Colletotrichum spp em frutos maduros Ficus carica L. cultivados entre novembro de 2011 e abril de 2012.

\begin{tabular}{cccccc}
\hline Novembro & Dezembro & Janeiro & Fevereiro & Março & Abril \\
\hline Salmão & $\begin{array}{c}\text { Salmão } \\
\text { empalidecido }\end{array}$ & $\begin{array}{c}\text { Salmão } \\
\text { empalidecido }\end{array}$ & Salmão & $\begin{array}{c}\text { Salmão } \\
\text { empalidecido }\end{array}$ & $\begin{array}{c}\text { Salmão } \\
\text { empalidecido }\end{array}$ \\
\hline
\end{tabular}

Em 2009 Gunawardhana et al realizaram estudos morfológicos de 40 isolados de C. gloeosporioides procedentes de Capsicum frutescens, Carica papaya, Mangifera indica, Persea americana, Ficus religiosa e Hevea brasiliensis e obervaram estas mesmas características morfológicas e tintoriais com variação na cor da colônia entre branco e cinza escuro. Ainda notaram mudança de cor na região central notadamente em isolados de Carica papaya.

Para Andrada et al (2007) as características que melhor distinguiram os isolados de C. gloeosporioides em mamão foram o formato cilíndrico ou abcláveo dos conídios, bem com sua relação comprimento/largura inferior a 3,9, e a produção de apressórios lobados ou fracamente lobados. Os mesmos autores lembram que a diferenciação entre espécies com base nas dimensões de conídios e apressórios é dificultada pela sobreposição, pois a maioria dos isolados de mamão apresentou dimensões dentro da faixa de variação descrita para as duas espécies, $C$. gloeosporioides e $C$. acutatum. Não sendo este, portanto, o melhor o critério de escolha para diferenciar estas duas espécies.

O genótipo dos isolados é determinante para as variações das colônias, uma vez que a expressão fenotípica está intimamente ligada ao local de cultivo e suas variações. Ao genótipo ainda é atribuído diferentes metabólitos secundários que tem sido caracterizado em Colletotrichum, permitindo o surgimento de variações tanto culturais quanto patogênicas. Este fatores caracterizam presença de Colletotrichum $s p$, o que pode surgir variações culturais e com potencial patogênico era o que defendia Bailey \& Jerger (1992).

Para Cai et al (2009) não é tão simples diferenciar espécie do complexo gloeosprorioides umas vez que em sua pesquisa apenas $14 \%$ das suas sequências designadas como $C$. gloeosporioides em GenBank são da espécie $C$. Gloeosporioides.

Uma única planta pode ser hospedeira de várias espécies de Colletotrichum. Em 2010 Phoulivong e colaboradores estudaram isolados deste fungo em oito frutos e confirmaram esta circunstância.

Soares, Lourenço \& Amorim (2008) realizaram uma pesquisa sobre Infecção de goiabas por Colletotrichum gloeosporioides e Colletotrichum acutatum sob diferentes temperaturas e períodos de molhamento e não foi constatada diferença estatística entre as espécies. A rápida germinação e formação de apressórios em ampla faixa de temperatura indicam habilidade das duas espécies em explorar condições noturnas, com temperaturas mais amenas e prolongado período de orvalho e diurnas, com altas temperaturas, que são características de situações de campo durante o verão.

O gênero Colletotrichum é capaz de causar infecção também em plantas de interesso na medicina como o cártamo (Carthamus tinctorius) que é uma espécie cultivada de importância medicinal e industrial e atualmente é considerada uma planta de grande potencial na produção de biodiesel. Carneiro et al (2012) verificaram qual o agente causal de lesões foliares de plantas sintomáticas e realizaram teste de patogenicidade dos isolados. A observação e análise de estruturas reprodutivas do patógeno em meio de cultura e no tecido do hospedeiro, assim como a PCR táxon-específica permitiram a identificação dos isolados do fungo como pertencentes à espécie Colletotrichum gloeosporioides.

Rosa, Serra \& Melo (2012) avaliaram lesões em frutos de pimenta depois das tapas de limpeza e desinfestação do material, fragmentos da região de transição, entre a lesão e os tecidos sadios transferindo-os para placas de Petri contendo meio de cultura BDA e, em seguida, incubados a $25 \pm 2^{\circ} \mathrm{C}$, sob alternância luminosa e posteriormente, os fragmentos do micélio das colônias foram transferidos para tubos contendo BDA e incubados nas mesmas condições. A análise da sequencia de do DNA ribosossomal confirmou ser Colletotrichum gloeosporioides o agente causador destas lesões.

Há relatos de infecção de feijoeiro por Colletotrichum lindemuthianum com considerada tolerância a agentes biológicos. Aplicação de extrato aquoso basidiocarpo de Pycnoporus sanguineus reduz a severidade da actracnose, em média, em $54 \%$ para a primeira folha trifoliolada tratada e inoculada e em $72 \%$ para a segunda folha apenas inoculada, indicando indução de resistência sistêmica (BALDO et al, 2011)

Serra et al (2011) fizeram um estudo sobre diversidade fenotípica, patogênica e identificação de espécies de Colletotrichum em mangueiras no Nordeste brasileiro e diagnosticaram ser as espécies gloeosporioides e acutatum as principais causadoras da antracnose.

Costa et al (2010) investigaram a incidência de Colletotrichum em colmos de genótipos de milho e evidenciaram a predominância de $C$. graminicola como agente causal na área do Centro Nacional de Pesquisa de Milho e Sorgo CNPMS - Embrapa em sete Lagoas - MG. Para estes autores a predominância de $C$. graminicola na safra 2006/2007 ocorreu, provavelmente, devido ao maior potencial de inóculo na área de plantio devido a ausência de diferenças significativas nas condições climáticas (temperatura, umidade relativa e precipitação) prevalecentes durante as safras de verão.

São inúmeras as plantações afetadas por fungos do gênero Colletotrichum e causam prejuízos econômicos e, sobretudo problemas fitossanitários. Macieras não estão fora do leque das plantas afetadas. Araújo \& Stadnik (2011), estudaram processos infecciosos nestas frutíferas e concluíram que $C$. gloeosporioides afetaram estas plantas mesmo sendo resistentes e suscetíveis à doença. Para eles, a variação do tempo é significativa para a germinação de conídios e formação de apressórios bem como para o vegetal sintetizar importantes enzimas como peroxidases (PODs) e GLU $\beta$-1,3-glucanases (GLUs) importantes do processo de defesa contra patógenos.

\section{CONCLUSÃO}

Foi possível concluir que o gênero do patógeno causador da podridão dos frutos de Ficus carica $L$. foi 
realmente um fungo do gênero Colletotrichum, não sendo possível neste momento identificar a espécie.

\section{REFERÊNCIAS BIBLIOGRÁFICAS}

ARAÚJO, L.; STADNIK, M. J. Processo infeccioso e atividade de enzimas em plântulas de macieira de genótipo resistente ou suscetível à mancha foliar de Glomerella causada por Colletotrichum gloeosporioides. Troical plant pathol, v.36, n.4, p.241-248, 2011.

BAILEY, J. A.; O'CONNELL, R. J.; PRING, R. J.; NASH, C. Infection strategies of Colletotrichum species. In: Bailey, A. J.; Jeger, J. M. Colletotrichum: biology, pathology and control. Oxford, British Society for Plant Pathology, p. 88-120, 1992.

BALDO, M. et al. Detecção in situ de espécies reativas de oxigênio em feijoeiro tratado com extratos de Pycnoporus sanguineus e inoculado com Colletotrichum lindemuthianum. Summa phytopathol, v.37, n.4, p.174179, 2011.

BONNET, L. P. et al. Caracterização morfocultural e infecção cruzada de Colletotrichum gloeosporioides agente causal da antracnose de frutos e hortaliças em pós-colheita. Ambiência, Guarapuava, v. 6, n.3, v.6. p. $451-463,2010$.

BRAND, S. C. et al. Extratos de alho e alecrim na indução de faseolina em feijoeiro e fungitoxicidade sobre Colletotrichum lindemuthianum. Ciência Rural, v.40, n.9, p.1881-1887, 2010.

CAI, L. et al. A polyphasic approach for studying Colletotrichum. Fungal Diversity, Indonesia, v. 39, n. 1, p. 183-204, 2009.

CARNEIRO, S. M. de T. P. G. et al. Ocorrência de Colletotrichum gloeosporioides (Penz.) Sacc. em Carthamus tinctorius L. no estado do Paraná. Summa phytopathol, v.38, n.2, p.163-165, 2012.

COSTA, R. V. da et al. Incidência de Colletotrichum graminicola em colmos de genótipos de milho. Summa phytopathol, v.36, n.2, p.122-128, 2010.

GUNAWARDHANA, P. L. T. et al. A phenetic analysis of Colletotrichum gloeosporioides isolates from selected host plants. Ceylon Journal of Science (Biological Sciences), Sri Lanka, v. 38, n. 2, p. 57-66, 2009.

KOTZ, TAILENE ELISA et al. Enxertia em figueira 'Roxo de Valinhos' por borbulhia e garfagem. Bragantia, Campinas, v.70, n.2, p.344-348, 2011.

LEONEL, S.; TECCHIO, M. A. Épocas de poda e uso da irrigação em figueira 'Roxo de Valinhos' na região de Botucatu, SP. Bragantia, Campinas, v. 69, n. 3, p. 571580, 2010.
MAIORANO. J. A. Figo. in Donadio, L. C. et al.(Org.). História da fruticultura paulista. p. 173-184. SBF. Jaboticabal: 2010.

PHOULIVONG, S. et al. Colletotrichum gloeosporioides is not a common pathogen on tropical fruits. Fungal Diversity, Indonesia, v. 44, n.1, p. 33-43, 2010.

SERRA, I.M.R.S. et al. Diversidade fenotípica e patogênica de Colletotrichum, agente causal da antracnose em mangueira, e identificação de espécie. Summa phytopathol, v.37, n.1, p.42-51, 2011.

SOARES, A. R.; LOURENÇO, S. A.; AMORIM, L. Infecção de goiabas por Colletotrichum gloeosporioides e Colletotrichum acutatum sob diferentes temperaturas e períodos de molhamento. Tropical plant pathol, v.33, n.4, p.265-272, 2008

SOUSA, R. M. S, DE; SERRA, I. M. R. de S.; MELO, T. A. Efeito de óleos essenciais como alternativa no controle de Colletotrichum gloeosporioides, em pimenta. Summa phytopathol, v.38, n.1, p.42-47, 2012. 